MATHEUS DE BARROS

\title{
As contribuições do realismo jurídico escandinavo para a teoria do direito contemporânea: um lugar para a máquina social
}

\author{
Dissertação de Mestrado \\ Orientador: Professor Associado Ari Marcelo Solon
}

Universidade de São Paulo

Faculdade de Direito

São Paulo

2019 
MATHEUS DE BARROS

As contribuições do realismo jurídico escandinavo para a teoria do direito contemporânea: um lugar para a máquina social

Dissertação apresentada à banca examinadora do Programa de Pós-graduação da Faculdade de Direito da Universidade de São Paulo como exigência parcial para obtenção do título de mestre em direito.

Área de concentração: Filosofia e Teoria Geral do Direito.

Orientador: Prof. Associado Dr. Ari Marcelo Solon

\section{Banca examinadora:}

Professor orientador:

Professor(a):

Professor(a):

Professor(a):

\section{Universidade de São Paulo}

Faculdade de Direito

\section{São Paulo}




\section{Catalogação da Publicação \\ Serviço de Biblioteca e Documentação \\ Faculdade de Direito da Universidade de São Paulo}

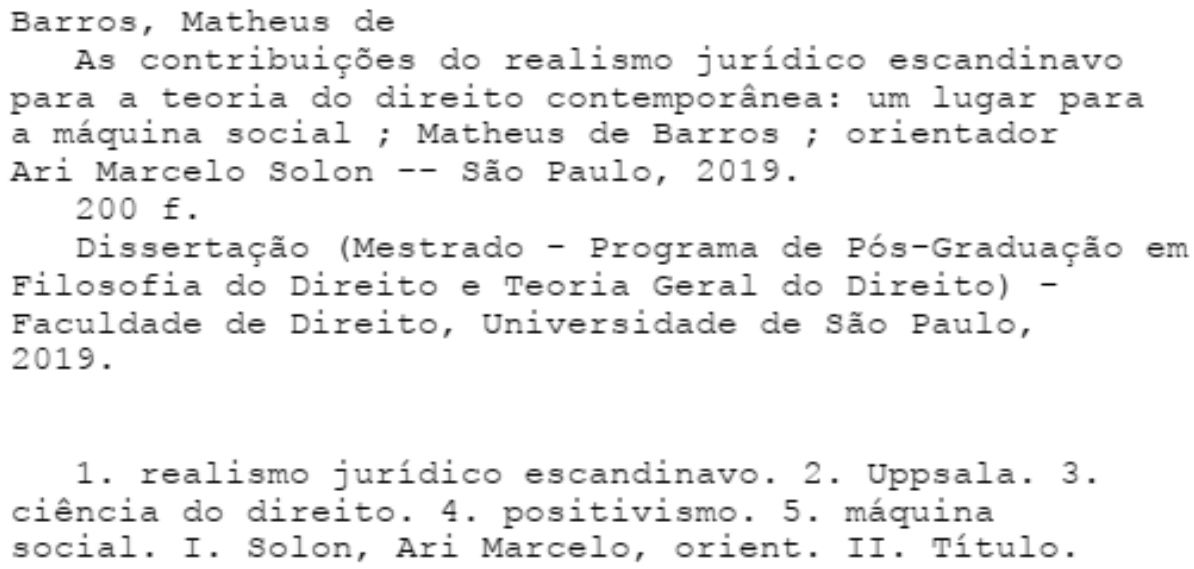


À minha família, que me forneceu todo o apoio e toda a compreensão de que eu precisava para escrever este trabalho. 


\section{AGRADECIMENTOS}

Nos últimos três anos, eu pude descobrir que a minha vocação profissional reside na pesquisa e, quem sabe um dia, na docência. Uso o termo "vocação" no sentido de entusiasmo com o aprendizado para a construção de uma carreira, entusiasmo esse que só surgiu e foi cultivado graças a todo o apoio que sempre recebi da minha família, a quem agradeço por estes meus primeiros passos.

Agradeço ao professor Ari Marcelo Solon, que me aceitou como orientando no mestrado no final de 2016 e, com isso, concedeu-me a oportunidade de escrever um trabalho sobre o realismo jurídico escandinavo sob a orientação de um dos maiores conhecedores do tema no país.

Agradeço aos professores Carlos Eduardo Batalha da Silva e Costa e Rafael Mafei Rabelo Queiroz, que, juntamente com o meu orientador, foram determinantes para colocar o meu projeto de pesquisa "nos trilhos", graças às suas recomendações no exame de qualificação.

Eu também dedico meus agradecimentos às professoras Marta Rodriguez de Assis Machado e Maíra Rocha Machado, com quem tenho aprendido os significados de pesquisar e ensinar o direito. Este trabalho foi produzido no contexto desse aprendizado.

Agradeço à minha namorada Valquíria Valio Simionato, que com muita paciência e atenção escutou minhas divagações sobre a teoria e a filosofia do direito. Nossas conversas e as suas leituras críticas constituíram contribuições inestimáveis para a redação desta dissertação.

Durante os três anos do mestrado, contei também com a atenção de vários amigos e amigas, que, direta ou indiretamente, ajudaram-me a levar adiante o mestrado, fosse por meio de discussões sobre o meu tema de pesquisa ou de conversas sobre qualquer outro assunto do mundo. 
Não basta abrir a janela

Para ver os campos e o rio.

Não é bastante não ser cego

Para ver as árvores e as flores.

É preciso também não ter filosofia nenhuma.

Com filosofia não há árvores: há ideias apenas.

Há só cada um de nós, como uma cave.

Há só uma janela fechada, e todo o mundo lá fora;

E um sonho do que se poderia ver se a janela se abrisse, Que nunca é o que se vê quando se abre a janela.

Alberto Caeiro (Fernando Pessoa), Poemas Inconjuntos

Não, nossa ciência não é uma ilusão. Ilusão seria imaginar que aquilo que a ciência não nos pode dar, podemos conseguir em outro lugar.

Sigmund Freud (1978 [1927], p. 128) 


\section{RESUMO}

BARROS, Matheus de. As contribuições do realismo jurídico escandinavo para a teoria do Direito contemporânea: um lugar para a máquina social. 2019. 200f. Mestrado - Faculdade de Direito, Universidade de São Paulo, 2019.

O realismo escandinavo é uma corrente teórica desenvolvida no século XX. A sua ideia basilar é a de que o direito é um fenômeno psicossocial (a "máquina social") apto a ser observado e explicado sem a utilização de pressupostos metafísicos (jusnaturalistas, idealistas) - trata-se, nesse sentido, de uma escola alinhada com as pretensões positivistas de consolidação de uma ciência sobre o direito. Este trabalho é um esforço para a compreensão das ideias dos pensadores responsáveis pelo realismo escandinavo: Axel Hägerström, Vilhelm Lundstedt, Karl Olivecrona e Alf Ross. Para tanto, um capítulo foi dedicado a cada um desses autores, de modo a possibilitar a apresentação dos papéis que eles tiveram na formação do movimento realista. O objetivo deste estudo é fornecer bases para possíveis respostas à questão "o realismo escandinavo pode contribuir para o debate contemporâneo sobre teoria do direito?”. Na parte final do trabalho, propõe-se que o realismo escandinavo seja compreendido como uma ponte entre a teoria jurídica e as ciências sociais.

Palavras-chave: realismo jurídico escandinavo; Uppsala; ciência do direito; positivismo; máquina social. 


\begin{abstract}
BARROS, Matheus de. The contribution from the Scandinavian Legal Realism to the contemporary legal theory: a place for the social machine. 2019.200p. Master - Faculty of Law, University of São Paulo, São Paulo, 2019.

Scandinavian Legal Realism is a theoretical school developed during the $20^{\text {th }}$ century. Its basic idea is that law is a psychosocial phenomenon (the "social machine") which can be observed and explained without metaphysical premises (natural law premises) - in this sense, it is a school of legal thought aligned with the positivist pretension of consolidating a legal science. This work is an effort to comprehend the ideas of those thinkers who were responsible for the Scandinavian Realism: Axel Hägerström, Vilhelm Lundstedt, Karl Olivecrona e Alf Ross. A chapter was destined to each of the authors, in a way that makes it possible to present the roles they had in the formation of the realist movement. The objective of this dissertation is to provide the basis for potential answers to the question "can Scandinavian Legal Realism contribute to the contemporary theoretical legal debate?". In the final part of this work, it is suggested that Scandinavian Legal Realism can be comprehended as a bridge between legal theory and social sciences.
\end{abstract}

Keywords: Scandinavian Legal Realism; Uppsala; legal science; positivism; social machine. 


\section{SUMÁRIO}

Introdução: Um esforço para a compreensão de ideias

Capítulo I: O pensamento de Axel Hägerström e um lugar para a psicologia nos estudos teóricos sobre 0 direito .......................................................................................................17

1. Algumas notas biográficas sobre Axel Hägerström .................................................. 17

2. Ceticismo: o niilismo axiológico e a teoria do erro (da falsidade) em Axel Hägerström

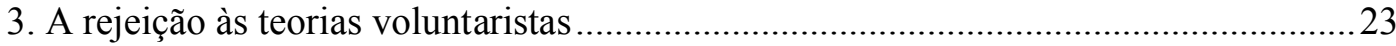

4. Direitos subjetivos e deveres segundo Hägerström ..................................................28

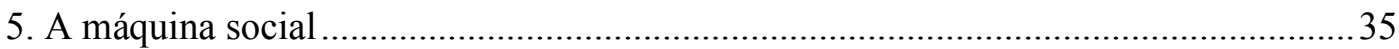

6. As contribuições de Hägerström para a teoria do direito contemporânea: um lugar para

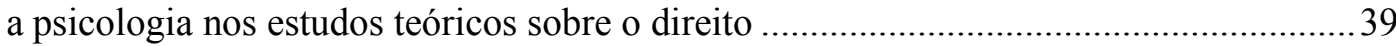

Capítulo II: O pensamento de Vilhelm Lundstedt: entre o realismo e o utilitarismo?

1. Algumas notas biográficas sobre Vilhelm Lundstedt .............................................4 44

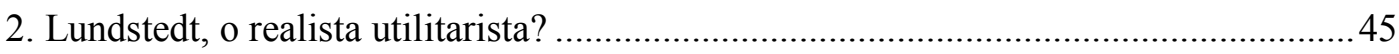

2.1. O bem-estar social: o indício de um estranho no ninho realista? ..........................46

2.1.1. O papel do legislador segundo Lundstedt .....................................................52

2.1.1.1. Juízes como (quase) legisladores ...........................................................54

2.1.2. O papel do teórico (do cientista) do direito segundo Lundstedt.........................57

2.1.2.1. A ameaça fantasma: superstições jurídicas no âmbito internacional ...............59

2.2. A ciência jurídica: apontamentos sobre o direito penal e o direito civil na visão de

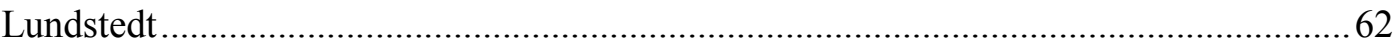

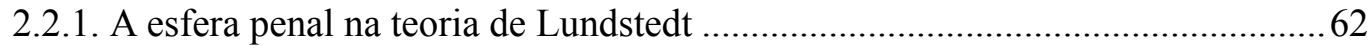

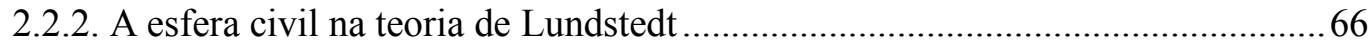

3. As contribuições de Lundstedt para a teoria do direito contemporânea: afinal,

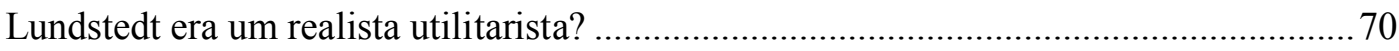

Capítulo III: O pensamento de Karl Olivecrona: fatos, linguagem, imperatividade e direito . 
1. Algumas notas biográficas sobre Karl Olivecrona. .79

2. Olivecrona, herdeiro de Hägerström e de Lundstedt: a continuação da missão contra o jusnaturalismo 80

3. A linguagem e a força: as inovações da teoria de Olivecrona .....................................85

3.1. O lugar da linguagem na realidade psicossocial: Cérbero, direitos e deveres.......86

3.2. Coerção livre de ilusão? Os imperativos independentes . .90

3.2.1. Os sinais do direito e do poder: o procedimento legislativo e a Constituição na

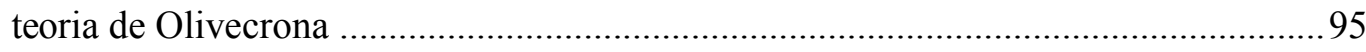

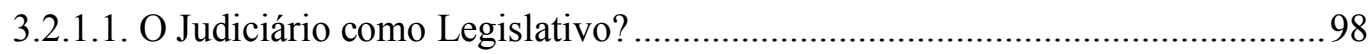

4. Correto, porém não verdadeiro: breves observações sobre afirmações concernentes

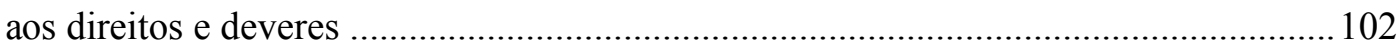

5. Uma máquina forte: coação, coerção e direito ......................................................... 104

5.1. A relação entre a moralidade e o direito ............................................................... 108

5.2. "O direito consiste principalmente em regras sobre força": Coação, coerção e as

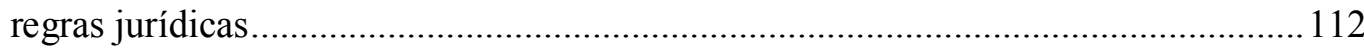

5.3. Uma máquina das nações? O direito internacional aos olhos de Olivecrona ...... 114

5.4. A força na segunda edição de Law as Fact . 115

6. As contribuições de Olivecrona para a teoria do direito contemporânea: uma máquina forte no horizonte de estudos teóricos e sociológicos 116

\section{Capítulo IV: O pensamento de Alf Ross: o realista com um conceito de validade... 122}

1. Algumas notas biográficas sobre Alf Ross

2. A primeira etapa do pensamento rossiano: o jovem Ross sob influência kelseniana. 125

2.1. O conhecimento jurídico segundo o jovem Ross: alguns pontos a esclarecer.

2.2. As fontes do direito segundo o jovem Ross

3. A segunda etapa do pensamento de Alf Ross: a elaboração de uma teoria da validade realista 135

3.1. A coerção e a coação, as experiências de validade e a relação simbiótica ........... 137

3.1.1. A moralidade e o Judiciário na teoria rossiana

3.2. Três observações sobre a teoria das fontes e a obrigatoriedade do direito na segunda fase do pensamento rossiano

144

3.2.1. Semelhanças e diferenças entre o realismo rossiano e o realismo estadunidense. 144 
3.2.2. O amadurecimento da apresentação do "método lógico-transcendental" 146

3.2.3. Esclarecimentos sobre a validade jurídica e a validade moral ......................... 146

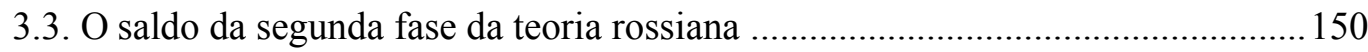

4. A terceira etapa do pensamento de Alf Ross: validade, vigência, predição e $T \hat{u}$ Tû. 152

4.1. Acenos ao Círculo de Viena e ao realismo americano, mas de mão dada com a

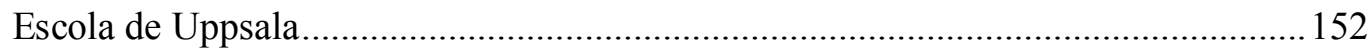

4.2. Validade, vigência e predição........................................................................ 158

4.2.1. Validade: consciência jurídica material, consciência jurídica formal e

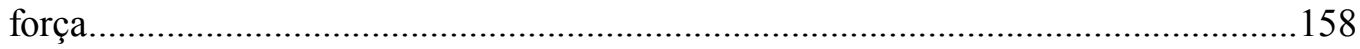

4.2.1.1. Weber e o realismo escandinavo: uma possibilidade de combinação de lentes

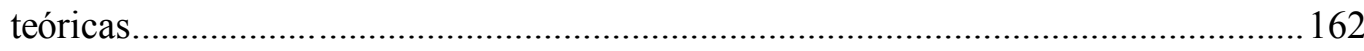

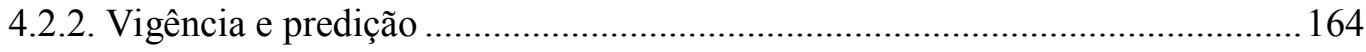

4.2.2.1. Vigência do direito: "mais do mesmo" disfarçado? ....................................... 167

4.3. Termos tĥu-t : vazio semântico e discurso jurídico .............................................. 172

5. Algumas considerações sobre Alf Ross e a sua incursão nos âmbitos da filosofia da

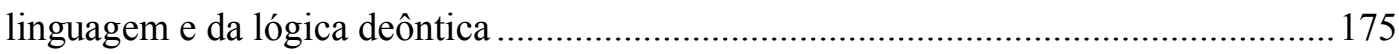

6. As contribuições de Ross para a teoria do direito contemporânea: o outro lado da validade e os usos de termos $t \hat{u}$ - $t \hat{u}$.

Considerações Finais: Um lugar para a máquina social do direito .............................. 181

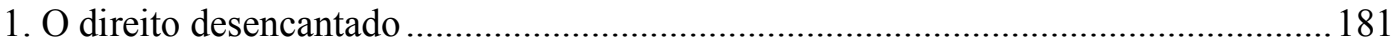

2. As ideologias dos realistas: contradição e/ou condição humana?.............................. 184

3. Realismo jurídico escandinavo: um exagero epistemológico? .................................187

4. Um lugar para a máquina social do direito: a ponte entre teoria jurídica e ciências sociais 



\section{INTRODUÇÃO: Um esforço para a compreensão de ideias}

Já nas cadeiras das faculdades de direito, aprendemos sobre a oposição entre jusnaturalistas e positivistas e sobre como essa divergência histórica assumiu diferentes nomes e nuances no decorrer dos anos. Este trabalho trata dessa antiga arena de embate entre ideias, sendo o resultado de estudos sobre o realismo jurídico escandinavo, que também pode ser denominado Escola de Uppsala. Como será mostrado nas linhas e páginas que se seguem, os escritos de Axel Hägerström, Vilhelm Lundstedt, Karl Olivecrona e Alf Ross formaram um movimento teórico alinhado com a missão positivista de desmistificação do direito. Esta dissertação se propõe a reconstruir as propostas que formaram esse movimento. Mas primeiro é necessário apresentar o que se entende, de modo geral, por jusnaturalismo e positivismo jurídico.

O jusnaturalismo pode ser caracterizado como um discurso sobre critérios metafísicos que confeririam validade ao direito. No decorrer dos séculos, diferentes critérios foram propostos: a magia advinda dos deuses, a recta ratio, a vontade de Deus, a razão moderna, a vontade do povo ou da nação, a objetividade moral observada em uma comunidade, entre outros. Para um jusnaturalista, a referência a algum desses supostos elementos da natureza ou da sociedade possibilita a avaliação da validade ou da correção de determinada norma. Por isso, os discursos jusnaturalistas se baseiam na duplicidade de dimensões jurídicas (o direito natural e o direito positivo) e na superioridade de uma dimensão sobre a outra (o direito natural superior ao positivo).

De modo geral, também podemos dizer que os positivistas almejam constituir uma linha de estudos jurídicos pautada na observação de fatos e na identificação de normas, sem que para tanto seja necessário recorrer a referências de algum tipo de direito natural (a critérios metafísicos de validade ou correção). Posta com outras palavras, a missão positivista é caracterizar o direito sem as mistificações jusnaturalistas - se os autores alinhados com o positivismo conseguiram ou não se libertar das amarras metafísicas é outra história.

Os realistas escandinavos, como mencionado anteriormente, constituíram uma escola de pensamento jurídico pertencente ao âmbito positivista. Suas obras traduzem um esforço teórico muito peculiar, consistente na caracterização do direito como um fenômeno psicológico e social, que foi apresentado por meio da metáfora da máquina social do direito. De acordo com o que será exposto nos quatro capítulos deste trabalho, a base 
epistemológica do esforço realista pode ser denominada naturalismo ontológico, que é o entendimento de que somente é realmente existente aquilo que compõe a estrutura do universo (fatos observáveis pelas diferentes ciências). Nota-se, então, que os elementos que formariam algum tipo de direito natural são rejeitados no esquema existencial do realismo escandinavo.

No Brasil, o realismo escandinavo não ocupa uma posição de destaque nos estudos jurídicos - talvez isso também seja verdade em boa parte do mundo. No entanto, dizer que a corrente teórica em questão foi esquecida seria um exagero. É mais adequado afirmar que ela é marginalizada, ficando à sombra dos grandes debates sobre a teoria do direito dos séculos XX e XXI - por exemplo, o debate atual sobre o que se convencionou chamar de pós-positivismo ou de neoconstitucionalismo. Admitindo-se esse cenário, por que estudar o realismo jurídico escandinavo? A sua marginalização não seria um indício de fracasso, o resultado de uma espécie de "seleção natural" que proporciona a sobrevivência das correntes de pensamento mais úteis ao enfrentamento de perguntas teóricas e filosóficas de cada época?

No que concerne à primeira questão, a marginalização do realismo jurídico escandinavo nos debates teóricos contemporâneos é a razão para a produção deste estudo. Com isso, não se pretende afirmar que não há pesquisas relevantes sobre o tema, mas tão somente que essas não são numerosas, o que talvez se deva ao fato de que, geralmente, o realismo jurídico escandinavo não é detidamente abordado durante o ensino do direito. Por isso, uma pesquisa sobre as ideias realistas se mostrou uma oportunidade de investigação de um terreno relativamente pouco explorado no qual alguns objetos valiosos poderiam ser encontrados.

Tendo em consideração a segunda questão, a utilidade ou a inutilidade atual do realismo escandinavo poderá ser afirmada por eventuais leitores e leitoras deste trabalho. As minhas considerações finais consistem em uma avaliação que somente foi possível após a imersão nas leituras dos textos dos realistas, mas eu não tenho a ambição de propor uma verdade última sobre o tema. A minha maior expectativa é a de que esta dissertação auxilie leitoras e leitores na compreensão do realismo, o que possibilitará a produção de juízos embasados sobre o lugar que essa escola (não) tem atualmente.

As duas perguntas que orientaram a redação dos próximos capítulos foram: “O realismo escandinavo tem contribuições para oferecer aos debates teóricos contemporâneos? Se sim, quais são elas?". Deve-se depreender, da primeira pergunta, que 
o objeto das minhas investigações é o realismo escandinavo, que é aqui entendido como uma escola (um movimento), sendo que o modo de levar adiante tais investigações foi estudar as obras dos quatro grandes realistas: Hägerström, Lundstedt, Olivecrona e Ross.

Ainda com relação à primeira pergunta, é preciso esclarecer o que se entende por "debates teóricos contemporâneos". Trata-se do conjunto de produções acadêmicas (pesquisas, cursos, eventos para discussões organizados em faculdades) voltadas para temas pertencentes à teoria ou à filosofia do direito. Saliento que não tive a pretensão de transformar o atual cenário, mas apenas buscar entender se o realismo jurídico escandinavo poderia ocupar lugar relevante em nossos dias, no Brasil.

O método de trabalho empregado foi a revisão bibliográfica. Por isso, não se deve entender a mera reprodução reformulada do que foi escrito pelos autores, nem a simples glosa dos textos que foram por mim lidos para a produção destas páginas. A revisão bibliográfica é um esforço para a compreensão de ideias. Nesse sentido, os argumentos dos autores concernentes ao fenômeno psicossocial do direito são por mim reconstruídos, isto é, apresentados por meio do esforço de compreender a lógica interna das ideias propostas pelos realistas. Esse exercício me permitiu expor o fluxo do movimento realista, bem como me proporcionou identificar pontos que podem ser considerados problemáticos na Escola de Uppsala.

O leitor ou a leitora encontrará a seguir o resultado de tal esforço, que consistiu na leitura e na reflexão sobre as principais obras dos realistas escandinavos (os livros e os artigos nos quais aqueles autores expuseram e reformularam as suas teorias). As justificativas para a escolha do material de leitura serão expostas no decorrer dos capítulos, por meio da alusão aos textos e às contribuições que eles proporcionaram ao desenvolvimento do fluxo do movimento realista. No que concerne aos escritos dos próprios autores, somente versões em inglês, espanhol e francês foram utilizadas. Isso se deve à minha falta de conhecimento do sueco, dinamarquês e alemão, que foram idiomas empregados pelos autores em alguns de seus escritos - outros foram produzidos em inglês. Dessa forma, nem sempre a leitura de textos originais foi possível, sendo o caso de se reconhecer que isso não é o ideal. Ainda assim, a utilização de traduções não comprometeu o aludido esforço de compreensão de ideias, que também contemplou livros, artigos e teses sobre o realismo jurídico escandinavo.

Este trabalho foi organizado em quatro partes, além das considerações finais. Cada uma delas é dedicada ao pensamento de um realista escandinavo, que constitui uma parcela 
do conjunto das propostas teóricas formadoras da Escola de Uppsala. Apesar de esse conjunto não ser desprovido de divergências e contradições, é possível dizer que ele possui um núcleo duro, que une os quatro autores: o compromisso com a cruzada contra a metafísica nos estudos jurídicos e com a descrição teórica da máquina social do direito, cujo funcionamento foi objeto de meus estudos durante o mestrado.

Feitas as considerações introdutórias, desejo aos potenciais adeptos ou críticos do realismo jurídico escandinavo uma boa leitura. 


\title{
CONSIDERAÇÕES FINAIS: um lugar para a máquina social do Direito
}

\author{
“Constituição íntima das cousas”... \\ "Sentido íntimo do universo"... \\ Tudo isto é falso, tudo isto não quer dizer nada. \\ É incrível que se possa pensar em cousas dessas. \\ É como pensar em razões e fins \\ Quando o começo da manhã está raiando, e pelos lados das árvores \\ Um vago ouro lustroso vai perdendo a escuridão. \\ Alberto Caeiro (Fernando Pessoa), O Guardador de Rebanhos
}

\section{O direito desencantado}

Os capítulos deste trabalho retratam uma cruzada à qual os realistas escandinavos se propuseram: a destruição da metafísica nos estudos teórico-jurídicos. Para criar esse retrato, foi necessário apresentar as ideias daqueles que formam o panteão do realismo: Hägerström, Lundstedt, Olivecrona e Ross, autores cujas obras culminaram na proposta do direito como uma máquina social ${ }^{229}$. Porém, como visto nas páginas que antecederam estas considerações finais, apesar do objetivo comum e de bases filosóficas compartilhadas entre os autores, a cruzada realista não foi desprovida de variações nas formulações de ideias sobre o fenômeno jurídico ${ }^{230}$. Espera-se que a leitura deste trabalho possa evidenciar o fato de que o movimento jusfilosófico em questão não deixa de ser um movimento (uma escola dotada de certa confluência de premissas e objetivos) em razão de tais variações, pois é possível identificar um núcleo duro que orientou as obras dos realistas escandinavos: a intensão de promoção do desencantamento do direito.

As constantes denúncias da presença de noções metafísicas (idealistas, jusnaturalistas) unem os quatro realistas, deixando em segundo plano as diferenças - que nem sempre são divergências - em seus pensamentos. Com relação a esse propósito

229 Sobre as posições de destaque de Hägerström, Lundstedt, Olivecrona e Ross, ver, por exemplo, Sherbaniuk (1962) e Spaak (2014). Esses quatro autores construíram o que hoje se denomina realismo jurídico escandinavo, movimento que abarca outros nomes, como Adolf Phalén (1884-1931) e Ingemar Hedenius (1908-1982). Infelizmente, não foi possível obter material suficiente para a produção de capítulos sobre esses dois autores, devido à pequena quantidade de textos disponíveis em inglês, francês, espanhol ou português. Sobre a influência do movimento realista fora da Suécia e da Dinamarca, mais especificamente na Noruega, ver Slagstad (1991).

${ }^{230}$ Para exemplificar essas variações, podemos adotar o pensamento de Hägerström, apresentado no capítulo I, como marco comparativo. Com relação ao fundador do realismo escandinavo, Lundstedt se diferenciou ao enfatizar o método do bem-estar social, enquanto Olivecrona enfatizou a força (coerção e coação) e os imperativos e Ross se preocupou com uma teoria da validade jurídica. 
destrutivo, a ideia de desencantamento do mundo ${ }^{231}$, elaborada por Max Weber, é útil à caracterização do movimento realista escandinavo:

Quanto mais o intelectualismo reprime a crença na magia, "desencantando" assim os fenômenos do mundo, e estes perdem seu sentido mágico, somente "são" e "acontecem", mas nada "significam", tanto mais cresce a urgência com que se exige do mundo e da "condução de vida", como um todo, que tenham uma significação e estejam ordenados segundo um "sentido" (WEBER, 2012 [1972], p. 344).

A tarefa de eliminar a crença na magia jurídica dependeu, como visto, da afirmação do naturalismo ontológico e do niilismo axiológico em prol da desmistificação da natureza do direito por meio de uma abordagem teórico-sociológica, que enfatiza os papéis da irracionalidade e da força (coerção e coação) na configuração do fenômeno social jurídico. Nesse sentido, é preciso reconhecer que o realismo escandinavo não se propôs somente a destruir, pois a formulação de uma abordagem teórica que vislumbra a utilidade da sociologia e da psicologia para a compreensão de uma das dimensões da nossa realidade social (a do direito) abriu portas a possíveis novos entendimentos sobre como diversos fatores (moralidade, respeito à tradição, internalização irrefletida de padrões de conduta, temor de sanções) constituem uma ordem jurídica. Em suma, este foi o modo pelo qual os realistas deram um novo sentido à teoria do direito: eles depuseram a metafísica e, em seu lugar, colocaram os fatos a serem estudados pela sociologia e pela psicologia, pois somente em fatos pode residir a natureza do direito.

Por um lado, a visão realista proporciona, atualmente, a formação de uma agenda de pesquisa jurídica empírica, com a conjugação de conhecimentos técnicos de diversas áreas, como o direito, a economia, a psicologia, a sociologia e a antropologia. As partes finais de cada um dos quatro capítulos deste trabalho buscaram mostrar a possibilidade de utilização do realismo jurídico escandinavo como marco teórico para estudos científicos do direito. É plausível, por exemplo, verificar no realismo escandinavo o potencial para integrar debates contemporâneos, como entre positivistas e pós-positivistas. No campo teórico dos dias atuais, a escola realista não estaria contraposta à corrente positivista hartiana. A mesma coisa não pode ser dita com relação ao que se convencionou denominar pós-positivismo ou neoconstitucionalismo, já que a análise dessa corrente através da lente

${ }^{231} \mathrm{O}$ "desencantamento do mundo" é um conceito criado por Weber, que permeia a parte mais tardia de sua obra. Pierucci (2003) dedicou um livro à análise das aparições desse conceito nos escritos do sociólogo. O trecho aqui transcrito, retirado do primeiro volume de Economia e Sociedade (WEBER, 2012 [1972]), também foi utilizado por Pierucci (2003, p. 105) para exemplificar a noção de desencantamento do mundo. 
realista implica identificação de noções jusnaturalistas que ocultam a realidade sobre o fenômeno jurídico ${ }^{232}$.

A integração do realismo escandinavo às discussões contemporâneas sobre teoria do direito não encontra obstáculos intransponíveis. No que concerne ao cenário brasileiro, os obstáculos residem no fato de que autores como Ross e Olivecrona são pouco utilizados na educação jurídica e em produções acadêmicas. Como afirmado na parte final do capítulo IV, a alteração desse estado de coisas é contingente. Como resultado da pesquisa que originou este trabalho, afirma-se que a máquina social do direito é apta a ocupar um lugar importante nos estudos jurídicos.

Por outro lado, o desencantamento do direito, no sentido aqui exposto, pode ser interpretado como um duro golpe contra a busca por um norte normativo em nossa sociedade. Afinal de contas, se não há moralidade a ser necessariamente seguida, se a objetividade moral é uma falácia e é impossível que autoridades tomem decisões moralmente corretas, a qual guia devemos recorrer para orientar os rumos normativos de nossa sociedade? O ser humano, cuja organização social é regida, principalmente, pela irracionalidade racionalizada (as experiências de validade, por exemplo) e pela combinação eficaz da coerção e da coação, torna-se uma criatura mais fraca, menos senhora de si mesma, uma engrenagem na máquina social ${ }^{233}$. Apresentada dessa forma, a situação de desamparo seria tal qual aquela transmitida por Edgar Allan Poe (1809-1849):

Minha mão grãos de areia segura/ com bem força, que é de ouro essa areia./ São tão poucos! Mas fogem-me, pelos/ dedos, para a profunda água escura./ Os meus olhos se inundam de pranto./ Oh! Meu Deus! E não posso retê-los,/ se os aperto na mão, tanto e tanto?/ Ah! Meu Deus! E não posso salvar/ Um ao menos da fúria do mar?/ O que vejo, o que sou e suponho/ será apenas um sonho num sonho? ${ }^{234}$

Caso a visão realista sobre o fenômeno psicossocial do direito esteja correta, os sonhos (as noções metafísicas) vão ruindo, um a um, até que restem somente a irracionalidade e a força. Os preciosos grãos de areia referidos por Poe - que no contexto

\footnotetext{
${ }^{232}$ Não ignoro a dificuldade de conceituar o pós-positivismo (neoconstitucionalismo), assim como não descarto o problema em afirmar que se trata de uma escola do pensamento jurídico. Minhas considerações, nesse ponto, remetem somente a autores que, como Dworkin, colocam-se como adversários daqueles que se identificam como positivistas, como Hart. Sobre esse embate, ver Shapiro (2007).

${ }^{233}$ Nesse sentido, ver Obedience to Authority: an experimental view, do psicólogo Stanley Milgram (19331984). Na obra em questão, por meio de experimentações controladas consistentes em observação de comportamentos de seres humanos, Milgram (1974) constatou o poder da noção de hierarquia na determinação de condutas de pessoas comuns.

${ }^{234}$ Utilizo aqui a tradução de Oscar Mendes e Milton Amado. Vide Poe (2009, p. 47-48). A versão original pode ser consultada em: https://www.poetryfoundation.org/poems/52829/a-dream-within-a-dream. Acesso em: 01 ago. 2019.
} 
deste trabalho são as orientações morais capazes de conferir ao direito a legitimidade e a certeza da segurança da decisão - se perdem na pretensão da consolidação de uma ciência jurídica capaz de descrever o que realmente é a ordem jurídica e em que ela se baseia.

Esse cenário dramático não é demasiadamente pessimista? A resposta a essa pergunta dependerá da necessidade individual: enquanto algumas pessoas precisam de um solo moral firme sobre o qual pisar, outras somente precisam saber que o solo é irregular e, em algumas trilhas, inconstante e perigoso. Conforme será argumentado a seguir, a segunda opção parece ter sido aquela admitida pelos seguidores de Hägerström, que, não obstante seus compromissos com a promoção de uma ciência realista do direito, tiveram em suas vidas momentos de engajamento ideológico.

\section{As ideologias dos realistas: contradição e/ou condição humana?}

A cruzada pelo desencantamento do mundo, em alguns momentos, assumiu ares de sacerdócio, tamanha a obstinação dos realistas em revelar à comunidade jurídica a verdade desprovida dos misticismos jusnaturalistas sobre a natureza do direito. Os termos "crença", "mágico", "idealismo", "jusnaturalismo" e "ideologia" são tratados, nos escritos realistas, como sinônimos que indicam a projeção de sentimentos e emoções humanas na teoria do direito. Não seria uma contradição, então, que realistas como Lundstedt, Olivecrona e Ross tenham se engajado, cada um à sua maneira, ideologicamente em questões sociais?

Como vimos, Lundstedt foi um parlamentar do partido socialdemocrata e, ao fazer política, agia ideologicamente em prol do que julgava ser o bem-estar social. Olivecrona também forneceu amostras significativas de seu posicionamento político ao se manifestar favoravelmente ao regime nazista alemão durante a Segunda Guerra Mundial, pois ao afirmar que o destino da Europa seria melhor nas mãos da Alemanha do que nas da Inglaterra, ele necessariamente fez juízos sobre o que seria bom para a comunidade europeia, o que pressupõe valorações morais. Ross, por sua vez, também não deixou de agir ideologicamente. A maior prova disso é a obra Why Democracy?, a qual Ross (1989 [1952], p. 11) destinou, logo na primeira linha do prefácio, "às pessoas democráticas",235. Foi por meio da versão em inglês daquele livro que o autor buscou apresentar aos seus leitores estadunidenses a socialdemocracia (orientação política dinamarquesa àquela época), distinguindo-a do regime comunista. O engajamento político de Ross é patente

\footnotetext{
${ }^{235}$ Utilizo aqui a tradução espanhola: "Este libro está destinado a las personas democráticas."
} 
naquela obra, que foi publicada em inglês no tempo da Guerra Fria: ele repudiou o nazismo, o fascismo, o comunismo soviético e o capitalismo desenfreado (sem preocupações sobre igualdades sociais por parte do governo), pregando a defesa de liberdades, o "respeito pelo ser humano que há em todo indivíduo", a "solidariedade" e a luta pela democracia em prol de "uma sociedade mais feliz e mais justa" (ROSS, 1989 [1952], p. 242 e 246) ${ }^{236}$. Não seria isso uma evidência de metafísica no pensamento de Ross? Segundo o próprio autor, sim: suas considerações sobre a necessidade da democracia constituiriam "uma interpretação metafísica da vida", restando àqueles comprometidos exclusivamente com a ciência "guardar silêncio" sobre o assunto (ROSS, 1989 [1952], p. 242) ${ }^{237}$. Aliás, a existência de um espírito ideológico-prescritivo no pensamento de Ross pode ser observado, inclusive, em um de seus escritos dotados de propósitos científicos. Em uma passagem de Sobre o Direito e a justiça referente ao papel do direito no direcionamento moral de uma sociedade, o autor afirmou que "os homens devem ser livres para realizar aqueles atos que não concernem aos demais, ainda que as pessoas os considerem [os atos] pecaminosos" (ROSS, 1997 [1958], p. 453) ${ }^{238}$. Com isso, o realista mostrou inequivocamente o seu posicionamento moral sobre as liberdades individuais.

As atitudes motivadas por juízos de valor, que se traduzem na exteriorização de postulados sobre a vida política, não constituiriam uma contradição frente à proposta realista de erradicação do jusnaturalismo no estudo do fenômeno social jurídico? Ao prescrever o silêncio dos cientistas em matéria de ideologia política posta em prática, Ross não teria se contradito e se tornado um idealista, assim como teria ocorrido com Lundstedt e Olivecrona?

Realmente, não parece ser absurda a crítica hipotética consistente no apontamento de que os realistas, na dimensão prática do cotidiano político existente em todas as sociedades, abandonaram o niilismo axiológico. Esse abandono, então, seria uma contradição quanto às pretensões de uma ciência realista do direito, visto que os próprios cientistas não seriam capazes de se desembaraçar dos laços ideológicos que os prendem à

\footnotetext{
236 Tradução livre do espanhol: "[...] el respeto por el ser humano que hay en todo individuo, y en una estrecha solidariedad con él" (ROSS, 1989 [1952], p. 242). Eis o outro trecho citado parcialmente: "Todos somos igualmente responsables por su resultado. No es sólo nuestra libertad la que está en disputa, sino también el sueño de una sociedad más feliz y más justa” (ROSS, 1989 [1952], p. 246).

237 Tradução livre de partes deste trecho: "Estamos aqui en el borde mismo de una interpretación metafisica de la vida, y quien desee permanecer en el terreno de la ciencia, haría mejor en guardar silencio."

238 Tradução livre do seguinte trecho: "[...] los hombres deben ser libres de realizar aquellos actos que no conciernen a los demás, aunque éstos los consideren pecaminosos."
} 
vida em sociedade. Porém, outra interpretação pode ser dada ao fato de que autores como Lundstedt, Olivecrona e Ross manifestaram seus ideais no âmbito político: isso não seria nada mais que uma expressão da condição humana.

Ao proporem uma ciência do direito com base no naturalismo ontológico e no niilismo axiológico, os realistas construíram a ideia de que as valorações morais (juízos de valor) jamais poderiam ser verdadeiras ou falsas, por não corresponderem a entidades componentes da estrutura do universo. Por outro lado, eles não negaram que a produção de valorações morais seja inerente à convivência humana, ainda que os produtos (os juízos de valor, os ideais) não encontrem correspondência imutável no espaço-tempo. Ao contrário, a moralidade é um elemento que os quatro realistas reputaram essencial ao funcionamento da máquina social do direito, justamente porque a racionalização de sentimentos é um traço marcante do comportamento humano ligado intrinsecamente à internalização de normas jurídicas e morais. Nesse sentido, a razão humana não revela verdades sobre postulados morais a serem seguidos, mas a sua manifestação no cotidiano constitui uma verdade sobre a nossa condição: a moral é o resultado da convivência de seres humanos, racionalizações voltadas para a consolidação da coesão social ${ }^{239}$. Sendo animais racionais, nós desenvolvemos esse instrumento em prol da sobrevivência por meio da convivência. Com isso, não se afirma que essa convivência não possa ser conflituosa, já que temos diversos exemplos de divergências morais em nossa sociedade (os embates políticos durante eleições ou as divergências no tocante à política de enfrentamento ao tráfico de drogas, por exemplo). Ainda assim, o tecido social que permite a vida em comum de tantas pessoas depende da moralidade, que, a partir de uma visão realista, é uma ilusão proporcionada pela racionalidade - aqui, o termo "ilusão" não carrega um sentido pejorativo.

Com base no exposto no parágrafo anterior, pode-se afirmar que as atuações políticas (morais, idealistas) dos realistas foram manifestações da condição humana. Enquanto cientistas, eles adotaram o ponto de vista externo para descrever teoricamente a máquina social do direito. Por outro lado, os autores nunca negaram serem eles mesmos engrenagens da máquina. Por isso, talvez a melhor palavra para se referir à atuação moral dos realistas não seja contradição, mas sim tensão. Isso porque o teórico do direito, orientado pelo realismo escandinavo, encontra-se em uma situação na qual ele se propõe a observar cientificamente, com o máximo de objetividade, um fenômeno do qual ele mesmo

239 O papel da moralidade e do direito repressivo - notadamente o direito penal - na consolidação e na manutenção da coesão social foi apontado por Émile Durkheim (1858-1917) por meio do que ele denominou solidariedade mecânica (DURKHEIM, 1991 [1930], p. 73-78). 
faz parte - essa é a tensão comum a todos os ramos das ciências sociais. Ainda assim, é factível e plausível que alguém enxergue essa situação como contraditória. Diante desse possível questionamento, talvez nos reste admitir que a tensão seja contradição e, dessa forma, o próprio exercício de estudo da organização social humana seria contraditório. Isso não mudaria o fato de que uma pessoa pode olhar para si sem deixar de ser ela mesma, assim como um cientista social pode olhar para a sociedade sem deixar de a ela pertencer.

Nesse ponto, pode-se notar que essas considerações adentram o terreno da epistemologia. A pretensão realista de descrever a realidade do fenômeno social não estaria em alguma medida comprometida pela tensão decorrente da aludida condição humana? Não seria demasiadamente ambiciosa a missão de identificar uma realidade social? O próximo tópico se propõe a enfrentar essas questões.

\section{Realismo jurídico escandinavo: um exagero epistemológico?}

$\mathrm{Na}$ seção anterior, as manifestações dos realistas no campo político receberam atenção, pois, por serem amostras ideológicas, podem ser interpretadas como fatores em tensão com relação às pretensões científicas da Escola de Uppsala. Mas não seriam tais pretensões outro tipo de manifestação ideológica? Posta a questão de outro modo: a base epistemológica realista, consistente no naturalismo ontológico e no niilismo axiológico, não seria uma opção interpretativa da realidade decorrente de um ideal concernente ao conhecimento jurídico e, por isso, estaria sujeita a críticas similares àquelas que Hägerström e seus discípulos fizeram aos jusnaturalistas em geral?

Álvaro Pires (2010 [1997], p. 56) alerta contra o risco de o cientista social adotar radicalmente um modelo epistemológico, teórico ou metodológico a ponto de confundir tal modelo com a "própria imagem da ciência", relegando a todas as outras propostas divergentes a classificação de tentativas "primitivas" de produção científica. Tendo em mente as questões do parágrafo anterior, é de se questionar se a visão de realidade proposta pelos realistas é fruto da radicalização contra a qual Pires precaveu. A "redução" da realidade - com ênfase nas aspas - à estrutura do universo observável pelas ciências não seria uma ideologia epistemológica apresentada como uma verdade a partir da qual os estudos científico-jurídicos deveriam ser desenvolvidos? A busca por uma resposta a essas perguntas pressupõe algumas considerações sobre a instrumentalidade do realismo escandinavo nas dimensões epistemológica e metodológica. 
No que se refere ao plano epistemológico, o realismo escandinavo estabelece um critério para a identificação de algo como real: fatos passíveis de serem observados e descritos pelas ciências naturais e sociais. As implicações teóricas da aceitação desse critério foram expostas nos quatro primeiros capítulos deste trabalho e, por isso, elas não serão novamente abordadas. Neste momento, é necessário ressaltar que qualquer teoria que se propõe a discorrer, direta ou indiretamente, sobre a realidade do mundo em que vivemos terá de adotar critérios para definir aquilo que é real, e o realismo jurídico escandinavo não é diferente. Também é preciso notar que o embasamento da Escola de Uppsala no naturalismo ontológico e no niilismo axiológico foi um "esforço de objetivação e de divisão entre o verdadeiro e o falso", algo do qual as ciências sociais não podem prescindir em sua busca pelo "conhecimento sistemático do real válido empiricamente" (PIRES, 2010 [1997], p. 57 - destaque no original). Embora esse esforço não isente o realismo de críticas referentes ao seu modelo de realidade social, deve-se admitir não ser possível dizer que a proposta epistemológica da Escola de Uppsala é simplesmente arbitrária. Trata-se de uma construção da realidade capaz de fundamentar uma visão do fenômeno jurídico e estimular estudos sobre o direito. Nesse sentido, as seguintes palavras de Pires são úteis à compreensão do que se pretende comunicar nesta passagem deste trabalho:

Todas as observações do mundo empírico (científicas ou não) são impregnadas - em diferentes graus - de "teorias" (mais, ou menos válidas, conforme o caso). A orientação teórica dada à descrição de um conjunto de fatos objetivos numa pesquisa é sempre, portanto, uma forma de construção da realidade, mas isso não impede que haja construções mais válidas (tanto de um ponto de vista empírico quanto sob o ângulo dos valores), do que outras. [...] o projeto científico de construção do objeto não é necessariamente incompatível com a busca de uma determinada forma e de um certo grau de objetivação ou de precisão na descrição do real. Ele deve "dar conta" do real (PIRES, 2010 [1997], p. $58)$.

Dessa forma, pode-se dizer que o projeto realista de consolidação de bases teóricas para o desenvolvimento de uma ciência do direito dependeu da construção de um objeto (o fenômeno psicossocial jurídico) situado no universo ontologicamente definido por Hägerström. O apontamento, no plano teórico, de fatos constituintes de tal objeto é o que caracteriza o esforço de objetivação próprio das ciências sociais. Com isso, o realismo escandinavo "dá conta do real" ao fornecer formas e cores a um retrato da realidade a partir do qual o direito pode ser estudado sociologicamente, antropologicamente, psicologicamente etc. 
No tocante ao plano metodológico, as contribuições da Escola de Uppsala não são muito significativas em termos práticos de pesquisa. Embora o realismo escandinavo possa ser instrumentalizado epistemologicamente, de modo a ser adotado como a lente teórica através da qual o mundo é visto - este trabalho é um esforço de apresentação de tal visão -, é preciso reconhecer que o campo metodológico não foi muito explorado pelos realistas. A maior prova disso é o fato de que Hägerström, Lundstedt, Olivecrona e Ross não produziram pesquisas empíricas sobre o direito. Por isso, no que concerne aos modos pelos quais o conhecimento jurídico pode ser produzido por meio de estudos empíricos, é preciso se debruçar sobre a metodologia das ciências sociais, de maneira a possibilitar que a prática da pesquisa sobre o fenômeno psicossocial seja baseada na opção (na construção) de métodos adequados a cada investigação considerada individualmente ${ }^{240}$. Com isso, a instrumentalização epistemológica do realismo pode ser aliada à adoção de métodos empíricos de pesquisa com vistas à objetivação necessária a um compromisso com a prática das ciências sociais, o que nos leva ao próximo e último ponto deste trabalho ${ }^{241}$.

\section{Um lugar para a máquina social do direito: a ponte entre teoria jurídica e ciências sociais}

Enquanto revisão bibliográfica, o objetivo desta dissertação foi responder à pergunta "quais as contribuições do realismo jurídico escandinavo para a teoria do direito contemporânea?". Para tanto, a apresentação das teses que estruturam a Escola de Uppsala foi feita de modo a proporcionar a avaliação da possibilidade de situar o realismo nos debates atuais. A persistência da utilidade desse marco teórico já foi indicada em algumas passagens deste texto, podendo ser condensada na afirmação - que é o resultado da pesquisa - de que o realismo jurídico escandinavo pode ser uma ponte entre a teoria do direito e as ciências sociais (sociologia, psicologia, antropologia, ciência política, economia etc.). Nesse sentido, a obra formada pelo conjunto dos esforços de Hägerström,

\footnotetext{
240 Recentemente, Machado (2017) organizou uma publicação voltada especificamente para os estudos metodológicos destinados à pesquisa empírica em direito. É possível dizer que o direito é relativamente atrasado no desenvolvimento de métodos para pesquisas empíricas, se comparado com outras áreas do conhecimento científico, como a sociologia, a economia e a antropologia. Sobre as causas desse atraso, ver Nobre (2004) e Barros e Barros (2018).

241 "Considerando o tipo de descobertas feitas pelas ciências sociais, descobertas estas que consistem, geralmente, em desmistificar discursos justificadores de certas práticas institucionais, em questionar algumas falsas certezas e algumas formas de leitura espontânea e ilusória do social para deixar ver o que ocorre "realmente" e que está debaixo dos nossos olhos, é impossível não levar o debate, ao menos em grande parte, para o terreno empírico" (PIRES, 2010 [1997], p, 57).
} 
Lundstedt, Olivecrona e Ross é aqui entendida como uma produção teórica pertencente ao campo do positivismo jurídico, com uma abordagem pautada em uma observação externa do fenômeno psicossocial. No movimento realista, essa observação pode ter ênfase em diferentes elementos, por exemplo, a internalização psicológica do dever-ser, a força (coerção e coação) ou o papel da linguagem na configuração da dimensão jurídiconormativa de nossa sociedade. A diversidade de elementos enfatizados pelos quatro autores denota a pluralidade de leituras válidas de nossa realidade social e, por isso, o realismo escandinavo deve ser entendido como uma opção de lente teórica através da qual podemos enxergar o mundo. Contudo, a obtenção de uma visão sobre a realidade do fenômeno psicossocial não exaure a função da teoria realista. Isso porque, além de fornecer uma base epistemológica, o realismo convida ao desenvolvimento de pesquisas empíricas sobre o direito. Assim, podemos voltar nossos olhos para a máquina social, cuja existência se deve, racional e irracionalmente, a nós, as engrenagens. 


\section{REFERÊNCIAS}

AUSTIN, John. Lectures on Jurisprudence or the Philosophy of Positive Law. The Student's Edition. London: John Murray, 1880. Disponível em: https://archive.org/details/lecturesonjuris00campgoog. Acesso em: 11 fev. 2018.

AUSTIN, John Langshaw. How to do things with words: the William James Lectures delivered at Harvard University in 1955. URSOM, J. O. (ed). London: Oxford University Press, 1962.

BARROS, Matheus de. Realismo jurídico escandinavo e a noção de ponto de vista interno. Redes - Revista Eletrônica Direito E Sociedade, 2019. No prelo.

BARROS, Matheus de; BARROS, Marco Antonio Loschiavo Leme. Os desafios e os novos caminhos da pesquisa em direito no Brasil. Revista de Estudos Empíricos em Direito, São Paulo, v. 5, n. 1, p. 25-48, mar. 2018. Disponível em: http://reedpesquisa.org/revista/index.php/reed/article/view/177. Acesso em: 09 ago. 2019.

BENTHAM, Jeremy. An introduction to the principles of morals and legislation. Whitefish: Kessinger, 2005 [1781].

BENTHAM, Jeremy. Anarchical fallacies. Headline Series, n. 318, p. 56-67, 1998 [1796]. Disponível em: https://search.proquest.com/openview/8e5f00298e221b3b720f8a95c3069b8f/1?pqorigsite $=$ gscholar\&cbl=41871. Acesso em: 09 ago. 2019.

BJARUP, Jes. Reason, Emotion and the Law: studies in the philosophy of Axel Hägerström. 1982. 471 f. Tese (Doutorado em Direito) - Faculdade de Direito, Universidade de Edimburgo, Edimburgo, Escócia, 1982.

BJARUP, Jes. The philosophy of Scandinavian legal realism. Ratio Juris, v. 18, n. 1, p. 1 15, 2005.2 Disponível em: https://heinonline.org/HOL/Page?handle=hein.journals/raju18\&div=3\&g_sent=1\&casa_to ken=J12tcznz_eMAAAAA:6gAUok5GWvjMph5_mflkk5fYzfJHADMwmHyvoFf3HY5Q P1LGrM_sY_tWrQ3S8cUrwyr--ZIJRA\&collection=journals. Acesso em: 09 ago. 2019.

CAEIRO, Alberto (PESSOA, Fernando). O Guardador de Rebanhos. In: MARTINS, Fernando Cabral; ZENITH, Richard (eds.). Poesia completa de Alberto Caeiro. São Paulo: Companhia das Letras, 2005, p. 15-76.

CAEIRO, Alberto (PESSOA, Fernando). Poemas Inconjuntos. In: MARTINS, Fernando Cabral; ZENITH, Richard (eds.). Poesia completa de Alberto Caeiro. São Paulo: Companhia das Letras, 2005, p. 87-164.

CAPPI, Riccardo. A "teorização fundamentada nos dados": um método possível na pesquisa empírica em Direito. In: MACHADO, Maíra Rocha (Org.). Pesquisar empiricamente o direito. São Paulo: Rede de Estudos Empíricos em Direito, 2017, p. 391-422. Disponível em: http://reedpesquisa.org/publicacoes/volume-2-no-1-2014/. Acesso em: 09 ago. 2019. 
COTTERRELL, Roger. Northern lights: From Swedish realism to sociology of law. Journal of Law and Society, v. 40, n. 4, p. 657-669, 2013. Disponível em: https://onlinelibrary.wiley.com/doi/abs/10.1111/j.1467-6478.2013.00644.x. Acesso em: 09 ago. 2019.

COTTERRELL, Roger. The politics of jurisprudence revisited: a Swedish realist in historical context. Ratio Juris, v. 28, n. 1, p. 1-14, 2015. Disponível em : https://onlinelibrary.wiley.com/doi/abs/10.1111/raju.12064. Acesso em: 09 ago. 2019.

DURKHEIM, Émile. De la division social du travail. 2 ed. Paris: Quadrige/Presses Universitaires de France, 1991 [1930].

ELIASZ, Katarzyna; JAKUBIEC, Marek. The Vienna Circle and the Uppsala School as philosophical inspirations for the Scandinavian Legal Realism. Semina Scientiarum, v. 15, n. 1, p. 107-123, 2016. Disponível em: https://www.ceeol.com/search/articledetail?id=494034. Acesso em: 02 jul. 2019.

EVALD, Jens. Alf Ross: A Life. Tradução de Sarah Pedersen. Tilst: Djøf Publishing, 2014.

FARALLI, Carla. Law as Fact. Revus: Journal for Constitutional Theory and Philosophy of Law, n. 24, p. 57-67, 2014. Disponível em: https://journals.openedition.org/revus/3001. Acesso em: 19 jul. 2019.

FREUD, Sigmund. O Futuro de uma Ilusão. In: SALOMÃO, Jayme (org.). Os Pensadores: Freud. Tradução de José Octávio de Aguiar Abreu. 1978 [1927], p. 85-128.

FREUD, Sigmund. O Mal-Estar na Civilização. In: SALOMÃO, Jayme (org.). Os Pensadores: Freud. Tradução de José Octávio de Aguiar Abreu. São Paulo: Abril Cultura, 1978 [1929], p. 131-194.

FREUD, Sigmund. O Futuro de uma Ilusão. In: SALOMÃO, Jayme (org.). Os Pensadores: Freud. Tradução de José Octávio de Aguiar Abreu. 1978 [1927], p. 85-128.

FREUD, Sigmund. Totem e Tabu. In: SALOMÃO, Jayme (ed.). Edição Standard Brasileira das Obras Psicológicas completas de Sigmund Freud: Volume XIII. Rio de Janeiro, Imago Editora, 1996 [1913], p. 13-168.

GLASER, Barney G; STRAUSS, Anselm L. The discovery of grounded theory: strategies for qualitative research. New York: Aldine de Gruyter, 1967.

GUASTINI, Riccardo. Les juges créent-ils du droit?. Les idées de Alf Ross. Revus: Journal for Constitutional Theory and Philosophy of Law, n. 24, p. 99-113, 2014. Disponível em: https://journals.openedition.org/revus/3027. Acesso em: 17 jul. 2019.

HÄGERSTRÖM, Axel. General View. In: OLIVECRONA, Karl (ed.). Inquiries Into the Nature of Law and Morals. Traduzido por C.D. Broad. Uppsala: Almquist \& Wiksell, 1953a [1927], p. 1-16. 
HÄGERSTRÖM, Axel. Is Positive Law an Expression of Will?. In: OLIVECRONA, Karl (ed.). Inquiries Into the Nature of Law and Morals. Traduzido por C.D. Broad. Uppsala: Almquist \& Wiksell, 1953b [1916], p. 17-55.

HÄGERSTRÖM, Axel. On Fundamental Problems of Law. In: OLIVECRONA, Karl (ed.). Inquiries Into the Nature of Law and Morals. Traduzido por C.D. Broad. Uppsala: Almquist \& Wiksell, 1953c [1939], p. 348-366.

HÄGERSTRÖM, Axel. On the idea of duty. In: HÄGERSTRÖM, Axel. Philosophy and Religion. Tradução de Robert T. Sandin. London: George Allen \& Unwin Ltd, 1964a [1917], p. 97-172.

HÄGERSTRÖM, Axel. On the Question of the Notion of the Law. In: OLIVECRONA, Karl (ed.). Inquiries Into the Nature of Law and Morals. Traduzido por C.D. Broad. Uppsala: Almquist \& Wiksell, 1953d [1917], p. 56-256.

HÄGERSTRÖM, Axel. On the Truth of Moral Propositions. In: HÄGERSTRÖM, Axel. Philosophy and Religion. Tradução para o inglês de Robert T. Sandin. London: George Allen \& Unwin Ltd, 1964b, p. 77-96.

HART, Herbert L. A. Definition and theory in jurisprudence. In: HART, Herbert L. A. Essays in jurisprudence and philosophy. Oxford: Clarendon, 1983, p. 21-48.

HART, Herbert L. A. Discretion. Harvard Law Review, v. 127, p. 652-665, 2013. Disponível em: https://heinonline.org/HOL/Page?handle=hein.journals/hlr127\&div=19\&g_sent=1\&casa_t oken=VsHnKuf5wq8AAAAA:Ab6nD-

18KSjmjQiiTefKUyIFm8jjEzkevuZFOaKYpdlu8PO_ht8UxhIrcSE60akydiLNpmygow\&co llection=journals. Acesso em: 09 ago. 2019

HART, Herbert L. A. Essays on Bentham: studies in jurisprudence and political theory. Oxford: Clarendon, 1982.

HART, Herbert L. A. O Conceito de Direito. $6^{\text {a }}$ ed. Tradução de Armindo Ribeiro Mendes. Lisboa: Calouste Gulbenkian, 2011 [1994].

HART, Herbert L. A. Scandinavian realism. The Cambridge Law Journal, v. 17, n. 2, p. 233-240, nov. 1959.

HOLMES, Oliver Wendell. The path of the law. Harvard Law Review, v. 110, n. 5, p. 991-1009, [1897]. 1997 Disponível em: https://www.jstor.org/stable/1342108?casa_token=wLhdWj3MN6sAAAAA:MHLwWtDh OgX-2E04IH0wj4QeAs5X-

INsygYSLn4V8pwnXmKvbvrHN75ZdjrF002r4kchvdTmXWxbHmA6tObFf6xZWKMFv AmxVIpTKGj1SzMixX4SviNI\&seq=1\#metadata_info_tab_contents. Acesso em: 09 ago. 2019.

HOLTERMANN, Jakob. Naturalizing Alf Ross's Legal Realism. A Philosophical Reconstruction. Revus: Journal for Constitutional Theory and Philosophy of Law, $n$. 
24, p. 165-186, 2014. Disponível em: https://journals.openedition.org/revus/3087. Acesso em: 04 jul. 2019.

JAKOBS, Günther. Sociedad, norma y persona en una teoría de un Derecho penal funcional. Tradução de Manuel Cancio Meliá e Bernardo Feijóo Sánchez. Madrid: Civitas, 1996.

KELSEN, Hans. On the basis of legal validity. American Journal of Jurisprudence, v. 26, p. 178-189, 1981. Disponível em: $<$ https://heinonline.org/HOL/Page?handle=hein.journals/ajj26\&div=13\&g_sent $=1 \&$ casa_t oken=vy7BD5xnuHYAAAAA:NdSIxEsnxyUTuliotK2KoK6KAI1nkrtAvWknp2UGUdim FdaskQWJNmV8gybM5ifvoBjil7Hd4Q\&collection=journals $\geq$. Acesso em: 09 ago. 2019.

KELSEN, Hans. Pure theory of law. Tradução de Max Knight. 5. reimpressão. Clark, New Jersey: The Lawbook Exchange, 2005 [1967].

LEITER, Brian. Legal realisms, old and new. Valparaiso University Law Review, v. 47, p. 2012. 949-963, Disponível em: https://heinonline.org/HOL/Page?handle=hein.journals/valur47\&div=38\&g_sent $=1 \&$ casa_ token=-iAW-pxvSScAAAAA:JjSKuh_Xfc1JIMftj0FunJGMZd3dpN-

1Bp1E7NuLZQDjm2AadF12Z8zWCE5o1kjzWYPg9CR4mw\&collection=journals. Acesso em: 09 ago. 2019.

LUNDSTEDT, Anders Vilhelm. Legal Thinking Revised. Uppsala: Almquist \& Wiksell, 1956.

LUNDSTEDT, Anders Vilhelm. Superstition or rationality in action for peace? Arguments against founding a world peace on the common sense of justice: a criticism of jurisprudence. London: Longmans, Green and Co., 1925.

LUNDSTEDT, Anders Vilhelm. The Relation Between Law and Equity. Tulane Law Review, v. 25, p. 59-69, 1950. Disponível em: https://scholar.google.com.br/scholar?hl=ptBR\&as_sdt $=0 \% 2 \mathrm{C} 5 \& \mathrm{q}=$ LUNDSTEDT $\% 2 \mathrm{C}++$ Vilhelm. + The+Relation+Between+Law + an $\mathrm{d}+$ Equity\&btnG $=$. Acesso em: 09 ago. 2019.

LUNDSTEDT, Anders Vilhelm. The responsibility of legal science for the fate of man and nations. NYULQ Rev., v. 10, p. 326-340, 1933. Disponível em: https://heinonline.org/HOL/Page?handle=hein.journals/nylr10\&div=33\&g_sent $=1 \&$ casa_t oken=bb6vbNmR4noAAAAA:1BdkMmn9Hak7iok5e4ou8c_swh7q3VJ8x32zyzyiJg0AljB 4J6OIA3_7o5ubZsLzla3IRw_RnA\&collection=journals. Acesso em: 09 ago. 2019.

LYLES, Max. A call for scientific purity: Axel Hägerström's critique of legal science. 2006. Tese de Doutorado - Institutet för rättshistorisk forskning (The Ohlin Foundation for Legal History), Estocolmo, 2006.

MACHADO, Maíra Rocha (Org.). Pesquisar empiricamente o direito. São Paulo: Rede de Estudos Empíricos em Direito, 2017. Disponível em: http://reedpesquisa.org/publicacoes/volume-2-no-1-2014/. Acesso em: 09 ago. 2019.

MACKIE, John L. Ethics: inventing right and wrong. London: Penguin, 1977. 
MILGRAM, Stanley. Obedience to Authority: an experimental view. London: Tavistock, 1974.

MILL, John Stuart. Utilitarianism. New York: Oxford University Press, 2011 [1861].

MINDUS, Patricia. A Real Mind: the life and work of Axel Hägerström. Dordrecht: Springer, 2009.

MINDUS, Patricia. Social Tools and Legal Gears: Hägerström on the Nature of Law. In: ELIAESON, Sven; MINDUS, Patricia; TURNER, Stephen P. (eds). Axel Hägerström and modern social thought. Oxford: The Bardwell Press, 2014, p. 257-282.

NEVES, Marcelo. Entre Hidra e Hércules: princípios e regras constitucionais como diferença paradoxal do sistema jurídico. 2 ed. São Paulo: Editora WMF Martins Fontes, 2014.

NOBRE, Marcos. Apontamentos sobre a pesquisa em direito no Brasil. Cadernos Direito GV, n. 1, 2004. Disponível em: https://bibliotecadigital.fgv.br/dspace/handle/10438/2779. Acesso em: 09 ago. 2019.

OLIVECRONA, Karl. Bentham's "Veil of Mystery". Current Legal Problems, v. 31, n. 1, p. 227-237, 1978.

OLIVECRONA, Karl. ¿Inglaterra o Alemania?. Lübeck, 1941. Disponível em: https://archive.org/details/OlivecronaInglaterraOAlemania>. Acesso em: 09 ago. 2019.

OLIVECRONA, Karl. Is a sociological explanation of law possible?. Theoria, v. 14, n. 2, p. 167-207, 1948.

OLIVECRONA, Karl. Law as Fact. London: Oxford University Press, 1939. Disponível em: https://archive.org/details/in.ernet.dli.2015.275271. Acesso em: 09 ago. 2019.

OLIVECRONA, Karl. Law as Fact. 2 ed. London: Stevens \& Sons, 1971.

OLIVECRONA, Karl. Lenguaje jurídico y realidad. México, D.F.: Fontamara, 1991 [1962].

OLIVECRONA, Karl. Realism and idealism: Some reflections on the cardinal point in legal philosophy. NYUL Rev., v. 26, p. 120-131, 1951. Disponível em: https://heinonline.org/HOL/Page?handle=hein.journals/nylr26\&div=14\&g_sent $=1 \&$ casa_t oken=xMoQHSJfUYgAAAAA:IVfP5d6xTFB7hhfxLWCObJkkKS2UMnIC45O9mQw2K oK5ayK_CY5cbyBNZvM2QiVj4QPci4N9EA\&collection=journals. Acesso em: 09 ago. 2019.

OLIVECRONA, Karl. The imperative element in the law. Rutgers Law Review, v. 18, p. 794-810, $1964 . \quad$ Disponível em: https://heinonline.org/HOL/Page?handle=hein.journals/rutlr18\&div=55\&g_sent=1\&casa_t oken=\&collection=journals. Acesso em: 09 ago. 2019. 
OLIVECRONA, Karl. The Legal Theories of Axel Hägerström and Vilhelm Lundstedt. Scandinavian Studies in Law, v. 3, p. 125-150, 1959. Disponível em: http://www.scandinavianlaw.se/pdf/3-5.pdf. Acesso em: 09 ago. 2019.

OLIVECRONA, Karl. The Will of the Sovereign: Some Reflections on Bentham's Concept of a Law. Am. J. Juris., v. 20, p. 95-110, 1975. Disponível em: https://heinonline.org/HOL/Page?handle=hein.journals/ajj20\&div=10\&g_sent $=1 \&$ casa_to ken=ZOPNUnx 86JYAAAAA:I4X1ADWo0x2usk7LpbP1ROYtRTFHeph0w1zZH0Ne4lmWxYxlq0JfY42T2FNcrcHSu6FBGSABw\&collection=journals. Acesso em: 09 ago. 2019.

OLIVECRONA, Knut. De la peine de mort. Paris: A. Durand et Pedone-Lauriel, 1868. Disponível https://play.google.com/books/reader?id=OfOvlhCqFAUC\&hl=pt_BR\&pg=GBS.PP10. Acesso em: 05 fev. 2019.

OLSEN, Henrik Palmer. Prédiction et interprétation du droit. Revus: Journal for Constitutional Theory and Philosophy of Law, n. 24, p. 69-79, 2014. Disponível em: https://journals.openedition.org/revus/3055. Acesso em: 17 jul. 2019.

PETERSSON, Bo. Axel Hägerström and his early version of error theory. Theoria, v. 77, n. $1, \quad$ p. 55-70, 2011. Disponível em: https://onlinelibrary.wiley.com/doi/abs/10.1111/j.1755-2567.2010.01085.x. Acesso em: 09 ago. 2019.

PHILIPPI, Jeanine Nicolazzi. A lei: uma abordagem a partir da leitura cruzada entre direito e psicanálise. Belo Horizonte: Del Rey, 2001.

PIERUCCI, Antônio Flávio. O desencantamento do mundo: todos os passos do conceito em Max Weber. São Paulo: Editora 34, 2003.

PIRES, Álvaro P. Sobre algumas questões epistemológicas de uma metodologia geral para as ciências sociais. In: POUPART, Jean; DESLAURIERS, Jean-Pierre; GROULX, LionelH; LAPERRIÈRE, Anne; MAYER, Robert; PIRES, Álvaro P. Tradução de Ana Cristina Arantes Nasser. A pesquisa qualitativa: Enfoques epistemológicos e metodológicos. 2 ed. Petrópolis: Editora Vozes, 2010 [1997], p. 43-94.

POE, Edgar Allan. Poemas e ensaios. 4 ed. Tradução de Oscar Mendes e Milton Amado. Revisão técnica e notas de Carmen Vera Cirne Lima. Posfácio de Charles Baudelaire. São Paulo: Editora Globo, 2009.

RODRIGUES, Diogo Luiz Cordeiro. Alf Ross e seu Realismo Jurídico: uma resenha crítica. Revista de Estudos Constitucionais, Hermenêutica e Teoria do Direito (RECHTD), São Leopoldo, v. 8, n. 1, p. 117-125, jan./abr. 2016. Disponível em: http://www.revistas.unisinos.br/index.php/RECHTD/article/view/rechtd.2016.81.12/5324. Acesso em: 09 ago. 2019.

RODRIGUEZ, José Rodrigo; PÜSCHEL, Flavia Portella; MACHADO, Marta Rodriguez de Assis. O raciocínio jurídico-dogmático e suas relações com o funcionamento do Poder Judiciário e a democracia. In: RODRIGUEZ, José Rodrigo; PÜSCHEL, Flavia Portella; 
MACHADO, Marta Rodriguez de Assis (orgs.). Dogmática é conflito: uma visão crítica da racionalidade jurídica. São Paulo, 2012, p. 33-54.

ROMANINI, Mateus. Crítica de Karl Popper ao problema de indução e suas consequências para o princípio de verificabilidade. Kalagatos: Revista de Filosofia, Fortaleza, v. 10, n. 20, p. 305-335, jul./dez. 2013. Disponível em: https://doi.org/10.23845/kgt.v10i20.214. Acesso em: 03 jul. 2019.

ROSS, Alf. ¿Por que Democracia?. Tradução de Roberto j. Vernengo. Madrid: Centro de Estudios Constitucionales, 1989 [1952].

ROSS, Alf. Directives and Norms. London: Routledge \& Kegan Paul Ltd., 1968.

ROSS, Alf. Le concept de droit selon Hart. In: ROSS, Alf. Introduction à l'empirisme juridique: textes théoriques. Tradução de Eric Millard e Elsa Matzner. Paris: Bruylant, 2004 [1962], p. 183-190.

ROSS, Alf. Le problème des sources du droit à la lumière d'une théorie réaliste du droit. In: ROSS, Alf. Introduction à l'empirisme juridique: textes théoriques. Tradução de Eric Millard e Elsa Matzner. Paris: Bruylant, 2004 [1934], p. 23-37.

ROSS, Alf. On guilt, responsibility, and punishment. University of California Press, 1975.

ROSS, Alf. On the Illusion of Consciousness: Do Mental Data ('Phenomena of Consciousness') Exist?. Theoria, v. 7, n. 3, p. 171-202, dec. 1941.

ROSS, Alf. On the Logical Nature of Propositions of Value. Theoria, v. 11, n. 3, p. $172-$ 210, dec. 1945.

ROSS, Alf. Teoría de las fuentes del derecho: una contribución a la teoría del derecho positivo sobre la base de investigaciones histórico-dogmáticas. 1 reimpressão. Tradução de José Luis Muñoz de Baena Simón, Aurelio de Prada García e Pablo López Pietsch. Madrid: Centro de estudios políticos y constitucionales, 2007 [1929].

ROSS, Alf. The rise and fall of the doctrine of performatives. In: OLSON, Raymond E.; PAUL, Anthony M. (eds.). Contemporary philosophy in Scandinavia. Baltimore: The Johns Hopkins Press, 1972, p. 197-212. Disponível em: https://archive.org/details/contemporaryphil00olso. Acesso em: 19 jul. 2019.

ROSS, Alf. Tû-Tû. Harvard Law Review, v. 70, n. 5, p. 812-825, mar. 1957 [1951]. Disponível

em: https://www.jstor.org/stable/1337744?casa_token=KQ6Vkf49kaYAAAAA:0Zm7tkTrLgP kZ_BI8_jHKMKsGepC3mEVfyUn4hRttp9 fiSoIijhyfliKS2ZVuZKo84OPykbIvzxF3MIZ3 qv9PhhiJ3URDxojOLdicOq771s1yQZFStLA\&seq=1\#metadata_info_tab_contents. Acesso em: 09 ago. 2019.

ROSS, Alf. Hacia una ciencia realista del derecho: critica del dualismo en el derecho. Buenos Aires: Abeledo-Perrot, 1961 [1946]. 
ROSS, Alf. Sobre el derecho y la justicia. 2. ed. Buenos Aires: Editorial Universitaria de Buenos Aires, 1997 [1958].

ROSS, Alf; OLSEN, Henrik Palmer. The 25th Anniversary of the Pure Theory of Law. Oxford Journal of Legal Studies, v. 31, n. 2, p. 243-272, 2011 [1936].

RYDSTRÖM, Jens. Sweden 1864-1978: Beasts and Beauties. In: RYDSTRÖM, Jens; MUSTOLA, Kati (eds.). Criminally queer: Homosexuality and criminal law in Scandinavia 1842-1999. Aksant Academic Publishers, Amsterdam, 2007, p. 183-214.

SANDIN, Robert T. The founding of the Uppsala School. Journal of the History of Ideas, v. 23, n. 4, p. 496-512, oct./dez. 1962. Disponível em: https://www.jstor.org/stable/pdf/2708171.pdf?casa_token=Gg94mzne3qUAAAAA:9bh1C pT_NW1yddGZOCd5vLcHiUJeS6hdTnszXXV8_8OL0Aza3qtYBDpn9H7VlpPgMXFko BWCtcfq3r5tjQVP9XhjL5vJ5OJnrCxzHv8Lw20ank8zkF3E. Acesso em: 02 jul. 2019.

SANDSTRÖM, Marie. Law-Fact, Fiction or in between? Axel Hägerström's Quest for Legal Realism. Scandinavian Stud. L., v. 48, p. 329-339, 2005. Disponível em: https://pdfs.semanticscholar.org/65cc/465d12e7a02d870a3aaac5d896bade9dfa82.pdf. Acesso em: 09 ago. 2019.

SHAPIRO, Scott J., The Hart-Dworkin Debate: A Short Guide for the Perplexed (March 5, 2007). Disponível em: https://ssrn.com/abstract=968657. Acesso em: 01 ago. 2019.

SHERBANIUK, Douglas J. Scandinavian Realism. Alberta Law Review, v. 2, p. 58-75, 1962.

SIMÓN, José Luis Muñoz de Baena; GARCÍA, Aurelio de Prada; PIETSCH, Pablo López. Estudio Preliminar. In: ROSS, Alf. Teoría de las fuentes del derecho: una contribución a la teoría del derecho positivo sobre la base de investigaciones histórico-dogmáticas. 1 reimpressão. Tradução de José Luis Muñoz de Baena Simón, Aurelio de Prada García e Pablo López Pietsch. Madrid: Centro de estudios políticos y constitucionales, 2007, p. 2545.

SLAGSTAD, Rune. Norwegian Legal Realism Since 1945. Scandinavian Studies in Law, v. 35, p. 215-233, 1991. Disponível em: http://www.scandinavianlaw.se/pdf/358.pdf. Acesso em: 01 ago. 2019.

SOLON, Ari Marcelo. Dever Jurídico e Teoria Realista do Direito. Porto Alegre: Sergio Antonio Fabris Editor, 2000.

SPAAK, Torben. A critical appraisal of Karl Olivecrona's legal philosophy. London: Springer, 2014.

SPIERMANN, Ole. A National Lawyer Takes Stock: Professor Ross' Textbook and Other Forays into International Law. European Journal of International Law, v. 14, n. 4, p. 675-702, $\quad$ sept. 2003. Disponível em: https://academic.oup.com/ejil/article/14/4/675/542359. Acesso em: 19 jul. 2019. 
STAVROPOULOS, Nicos. The relevance of coercion: Some preliminaries. Ratio Juris, v. 22, n. 3, p. 339-358, 2009. Disponível em: https://onlinelibrary.wiley.com/doi/abs/10.1111/j.1467-9337.2009.00429.x. Acesso em: 09 ago. 2019.

SUNDELL, Jan-Olof. Vilhelm Lundstedt. A Biographical Sketch. Scandinavian Studies in Law, v. 48, p. 465-478, 2005. Disponível em: http://www.scandinavianlaw.se/pdf/4827.pdf. Acesso em: 09 ago. 2019.

TROPER, Michel. Ross, Kelsen et la validité. Droit et société, v. 50, n. 1, p. 43-57, 2002. Disponível em: https://www.cairn.info/revue-droit-et-societe1-2002-1-page-43.htm. Acesso em: 01 jul. 2019.

UEBEL, Thomas. Vienna Circle. The Stanford Encyclopedia of Philosophy. Spring 2019 [2006]. Disponível em: https://stanford.library.sydney.edu.au/entries/vienna-circle/. Acesso em: 03 jul. 2019.

WAABEN, Knud. Alf Ross 1899-1979: A biographical sketch. European Journal of International Law, v. 14, n. 4, p. 661-674, 2003. Disponível em: http://www.ejil.org/pdfs/14/4/438.pdf. Acesso em: 09 ago. 2019.

WEBER, Max. Economia e sociedade: fundamentos da sociologia compreensiva. Volume 1. 4 ed. Tradução de Regis Barbosa e Karen Elsabe Barbosa. Brasília: Universidade de Brasília, 2012 [1972].

ZAMBONI, Mauro. Law and Legal Politics: Vilhelm Lundstedt and the Law-Maker Function (August 2006). Disponível em: https://ssrn.com/abstract=927070. Acesso em: 20 fev. 2019. 